\title{
Does having an asthmatic sibling affect the quality of life in children?
}

\author{
Özge Yılmaz¹, Ahmet Türkeli², Özlem Karaca ${ }^{3}$, Hasan Yüksel ${ }^{1}$ \\ ${ }^{1}$ Division of Pediatric Allergy and Immunogy, ${ }^{3}$ Department of Pediatrics, Celal Bayar University, Manisa; ${ }^{2}$ Eskişehir State \\ Hospital, Eskişehir, Turkey.E-mail: hyukselefe@hotmail.com \\ Received: 22nd November 2016, Revised: 17th March 2017, Accepted: 20th March 2017
}

SUMMARY: Yılmaz Ö, Türkeli A, Karaca Ö, Yüksel H. Does having an asthmatic sibling affect the quality of life in children? Turk J Pediatr 2017; 59: 274-280.

Chronic illness in a family member leads to deterioration of quality of life in other members of that family. We aimed to investigate the influence of having an asthmatic sibling on a child's quality of life (QoL). We enrolled 2-12 year aged healthy children with an asthmatic sibling in the study group and healthy children with a healthy sibling in the control group of this cross-sectional study. Sociodemographic characteristics of children and disease severity characteristics of asthmatic siblings were recorded. All parents filled in Turkish generic PedsQLTM short form appropriate for the child's age group. Study and control groups had 114 children each. Total PedsQL ${ }^{\mathrm{TM}}$ scores were not significantly different in any of the age groups $(p=0.23, p=0.13, p=0.11$ respectively). Emotional PedsQL ${ }^{\mathrm{TM}}$ sub-scores in children with an asthmatic sibling were significantly worse $(83.0 \pm 16.5$ vs $91.6 \pm 10.9$ in the $2-4$ year age group, $72.0 \pm 17.8$ vs $92.2 \pm 11.6$ in the $5-7$ year age group, $73.7 \pm 24.1$ vs $88.7 \pm 14.8$ in the $8-12$ year age group respectively, $p \leq 0.002$ for all). Similarly, psychosocial sub-score was significantly lower in the 2-4 and 5-7-year-olds but not the 8-12 year old groups $(\mathrm{p}=0.01, \mathrm{p}=0.01, \mathrm{p}=0.08$ respectively). In conclusion, healthy children with asthmatic siblings have significantly lower emotional QoL and this needs to investigated for other chronic diseases in further research.

Key words: asthma, sibling, quality of life, PedsQL ${ }^{T M}$.

Chronic diseases in children lead to a deterioration in quality of life (QoL) and psychosocial well-being not only of patients themselves but also of their caregivers ${ }^{1-3}$. Severity of this deterioration is associated with many different sociocultural and economic factors as well as social support ${ }^{3}$. Many previous studies have assessed the influence of child's chronic disease on QoL and psychosocial well-being of parents and caregivers and demonstrated impairment in many aspects such as sleep, social functioning, daily activities, vitality, positive emotions, and depressive emotions $^{4-8}$. Similar psychosocial outcomes have been observed in siblings of children with a chronic disease and they were reported to have higher anxiety and depression as well as lower cognitive development and peer activities ${ }^{9}$. The change in the family dynamics with the diagnosis of a chronic disease in a child has impact on the healthy siblings of the ill child as well as the other family members. Moreover, this change in QoL is reported to be underestimated by the parents ${ }^{10}$. Increased behavioral and emotional symptoms in healthy siblings of chronically ill children were associated with worse quality of life $^{9}$. The influence of diseases which interfere with daily functioning and which require daily treatment were more prominent ${ }^{8,11}$. Parental care of the sick child and the way they treat his/her sibling may influence the psychosocial status and quality of life of the sibling. It has been demonstrated that rehabilitation programs for these siblings as well as the whole family members lead to better psychosocial and quality of life outcomes, emphasizing the need for routine assessment of the healthy siblings of children with chronic diseases for psychosocial well-being ${ }^{9}$. 
Since previous meta-analysis has demonstrated that illnesses that affect daily functioning resulted in negative effects on psychological functioning of siblings compared to diseases that do not effect daily functioning and since mild asthma has minimal influences on daily functioning we aimed to investigate the influence of mild asthma on the sibling's quality of life. Quality of life includes many different aspects such as physical, social and psychological; thus we aimed to obtain a larger view by evaluation of the QoL. Influence of mild persistent asthma on the sibling' QoL has not been studied in previous research, to our knowledge. Mild persistent asthma despite the chronicity of nature and daily requirement of treatment interferes less with daily activities of the patients when compared to chronic diseases like cancer. However, it is one of the most common chronic health problems among children ${ }^{12,13}$. The high prevalence of the disease as well as the above stated differences from many other chronic diseases necessitates individual research. Moreover, despite the milder nature of disease compared to the diseases investigated in previous research, parental attitude to the ill child and daily treatment requirement in a child may interfere with QoL in the sibling.

Therefore, in this study, we aimed to investigate the influence of having an asthmatic sibling on different aspects of a child's quality of life.

\section{Material and Methods}

This is a cross sectional study comparing QoL in healthy children with asthmatic and healthy siblings. The study was approved by the Instutional Review Board of Celal Bayar University (No: 2011-211) and we obtained written informed consent from the parents of the children enrolled.

\section{Study population}

We initially enrolled 150 healthy children without any chronic diseases that have asthmatic siblings to the study group; 50 children were enrolled for each of the 2-4, 5-7 and 8-12 year old groups. Control group composed of 151 healthy children without any chronic disease who presented to General Pediatrics outpatient department of the same university for healthy child follow up and who have healthy siblings; 51 in the 2-4 year age group and 50 in the other two age groups. All children were enrolled in the order of presentation to the respective department. The matching was done by enrolling the patient group first and control group after that.

The children in the two groups were enrolled considering the age range of the questionnaires. There are three different questionnaires for 2-4 years, 5-7 years and 8-12 years old children. Cases and controls were enrolled consecutively upon presentation to the department, matching according to these three age range. However, when enrollment was finished and mean ages were calculated, there was a difference between case and control groups because cases were nearer to the lower limit of the range and controls were closer to the upper limit of the range. Therefore, asthma and control groups were matched one to one and the final number of subjects in the asthma and control groups decreased to 114 each: 36 children in the $2-4$ year old, 40 in the 5-7 year old and 38 in the 8-12 year old groups each.

Exclusion criteria for both groups were; the presence of a chronic disease in another immediate family member, presence of an additional chronic illnesses besides asthma in the child and refusing to participate in the study.

\section{Data acquisition}

Sociodemographic characteristics such as age of the healthy child enrolled, age of the healthy or asthmatic sibling, parent education and occupation were recorded. Disease characteristics of the sibling with asthma such as age at diagnosis of asthma, number of asthma exacerbations and presentations to the hospital besides routine control during the previous three months period were recorded. All parents filled in the PedsQL ${ }^{\mathrm{TM}}$ Short Form 15 appropriate for the age of the child.

\section{PedsQL $L^{T M}$ questionnaire}

PedsQLTM Short Form 15 is a generic QoL questionnaire filled in by the parents that evaluates physical and psychosocial aspects of QoL in children ${ }^{14}$. There are three different forms for children aged 2-4, 5-7 and 8-12 years old. Validity and reliability of the questionnaires adapted to Turkish has been demonstrated ${ }^{15}$. The questionnaire is composed of 15 items; 5 items for physical functioning, 4 items 
for emotional functioning, 3 items for social functioning and 3 items for school functioning. Physical functioning items compose physical health summary subscale and the rest compose the psychosocial health summary subscale.

The items are answered on a Likert based scale that include "never", "almost never", "sometimes", "often" and "almost always" scored 0 to 4 respectively. For scoring purposes the responses are recoded as 100-75-50-25 and 0 . The total score and subscale scores are calculated by taking the mean value of the scores for each of the item composing that subscale. Higher scores indicate better QoL.

\section{Statistical analysis}

SPSS 15.0 computer program (IL) was used for the statistical analysis of data. Data were normally distributed thus are expressed as mean (standard deviation). Continuous variables such as age and PedsQL ${ }^{\mathrm{TM}}$ scores were compared with student's t test first Statistical significance was defined as a $\mathrm{p}$ value $<0.05$. Correlation analysis was carried out using Pearson correlation analysis.

Table I. Sociodemographic Characteristics of the Study Population.

\begin{tabular}{|c|c|c|c|}
\hline & Asthmatic sibling group & Healthy sibling group & $\mathrm{p}$ \\
\hline \multicolumn{4}{|l|}{ Sibling age $\dagger$} \\
\hline $2-4$ years age group & $3.3(0.8)$ & $3,3(0.8)$ & $1,00^{*}$ \\
\hline 5-7 years age group & $6.1(0.9)$ & $6.1(0.9)$ & $1.00^{*}$ \\
\hline $8-12$ years age group & $9.6(1.2)$ & $9.6(1.2)$ & $1.00^{*}$ \\
\hline \multicolumn{4}{|l|}{ Age $\dagger$} \\
\hline 2-4 years age group & $6.5(2.1)$ & $4.8(1.9)$ & $0.001^{*}$ \\
\hline 5-7 years age group & $6.9(3.2)$ & $5.3(2.6)$ & $0.02 *$ \\
\hline $8-12$ years age group & $7.0(2.9)$ & $5.4(2.1)$ & $0.007^{*}$ \\
\hline \multicolumn{4}{|l|}{ Age at diagnosis of asthma in sibling $\dagger$} \\
\hline 2-4 years age group & $3.4(1.8)$ & - & - \\
\hline 5-7 years age group & $4.2(3.1)$ & - & \\
\hline 8-12 years age group & $3.9(2.8)$ & - & \\
\hline \multicolumn{4}{|c|}{ Unscheduled hospital admissions for asthma in last 3 months $\dagger$} \\
\hline $2-4$ years age group & $0.5(0.8)$ & - & - \\
\hline 5-7 years age group & $0.6(0.7)$ & - & \\
\hline $8-12$ years age group & $0.3(0.8)$ & - & \\
\hline \multicolumn{4}{|c|}{ Number of asthma exacerbations in last 3 months $\dagger$} \\
\hline $2-4$ years age group & $0.5(0.7)$ & - & - \\
\hline 5-7 years age group & $0.6(0.7)$ & - & \\
\hline $8-12$ years age group & $0.2(0.5)$ & - & \\
\hline \multicolumn{4}{|l|}{ Mother education $\ddagger$} \\
\hline $2-4$ years age group & 36.1 & 44.4 & $0.47^{* *}$ \\
\hline 5-7 years age group & 32.5 & 30.0 & $0.81^{* *}$ \\
\hline $8-12$ years age group & 23.7 & 36.8 & $0.21^{* *}$ \\
\hline \multicolumn{4}{|l|}{ Father education } \\
\hline $2-4$ years age group & 47.2 & 63.9 & $0.16^{* *}$ \\
\hline 5-7 years age group & 32.5 & 45.0 & $0.25^{* *}$ \\
\hline 8-12 years age group & 39.5 & 34.2 & $0.63 * *$ \\
\hline
\end{tabular}

$\dagger$ Mean(standard deviation)

\$high school or above graduate (\%)

*Student's t test

${ }^{* *}$ Chi square test 


\section{Results}

\section{Sociodemographic Characteristics}

Mean ages at diagnosis of asthma in asthmatic siblings were $3.4 \pm 1.8$ years in $2-4$ age group and $4.2 \pm 3.1$ and $3.9 \pm 2.8$ years in 5-7 and 8-12 age groups respectively. Mean number of asthma exacerbations during the previous three months were $0.5 \pm 0.7,0.6 \pm 0.3$ and $0.2 \pm 0.5$ respectively (Table I).

Mother and father education was not significantly different in children with asthmatic and healthy siblings ( $p>0.05$ for all) (Table I).

Comparison of the quality of life scores of the groups

When children with asthmatic and healthy siblings were compared, physical, social or school subscale scores were not significantly different. Similarly, totals PedsQL ${ }^{T M}$ scores were not significantly different between children with asthmatic or healthy siblings in the 2-4, 5-7 and $8-12$ years' age groups $(p=0.21, p=0.13$, $\mathrm{p}=0.11$ respectively) (Table $\mathrm{II}$ ).

Mean emotional functioning sub-score in children with an asthmatic sibling was $83.0 \pm 16.5$ compared to $91.6 \pm 10.9$ in children with a healthy sibling in the 2-4-year age group $(p=0.01)$. Similarly, in 5-7 and 8-12 years old groups, mean emotional sub-score of children with an asthmatic sibling were $72.0 \pm 17.8$ and $73.7 \pm 24.1$ while those of the ones with a healthy sibling were $92.2 \pm 11.6$ and $88.7 \pm 14.8$ $(\mathrm{p}<0.001$ and $\mathrm{p}=0.002$ respectively) (Table II) (Fig. 1).

Table II. Mean PedsQLTM Scores in the Study Groups ${ }^{\mathrm{a}}$.

\begin{tabular}{|c|c|c|c|}
\hline & Asthmatic sibling group & Healthy sibling group & $\mathrm{p}^{\mathrm{b}}$ \\
\hline \multicolumn{4}{|l|}{ PedsQL TM total score } \\
\hline $2-4$ years age group & $88.7(12.1)$ & $92.1(10.7)$ & 0.21 \\
\hline 5-7 years age group & $85.2(9.3)$ & $89.2(10.6)$ & 0.13 \\
\hline $8-12$ years age group & $86.4(12.9)$ & $90.9(11.3)$ & 0.11 \\
\hline \multicolumn{4}{|l|}{ PedsQL TM physical functioning score } \\
\hline $2-4$ years age group & $96.6(10.9)$ & $92.8(12.3)$ & 0.17 \\
\hline 5-7 years age group & $94.0(10.9)$ & $91.3(10.8)$ & 0.26 \\
\hline $8-12$ years age group & $91.2(14.2)$ & $93.3(9.7)$ & 0.45 \\
\hline \multicolumn{4}{|l|}{ PedsQL TM emotional functioning score } \\
\hline $2-4$ years age group & $83.0(16.5)$ & $91.6(10.9)$ & 0.01 \\
\hline 5-7 years age group & $72.0(17.8)$ & $92.2(11.6)$ & $<0.001$ \\
\hline $8-12$ years age group & $73.7(24.1)$ & $88.7(14.8)$ & 0.002 \\
\hline \multicolumn{4}{|l|}{ PedsQL TM social functioning score } \\
\hline $2-4$ years age group & $90.3(17.9)$ & $91.2(11.8)$ & 0.79 \\
\hline 5-7 years age group & $85.0(19.6)$ & $89.1(12.1)$ & 0.28 \\
\hline $8-12$ years age group & $92.8(14.1)$ & $90.6(14.5)$ & 0.51 \\
\hline \multicolumn{4}{|l|}{ PedsQL TM school functioning score } \\
\hline $2-4$ years age group & $96.4(9.4)$ & $90.2(13.8)$ & 0.31 \\
\hline 5-7 years age group & $90.9(15.3)$ & $88.9(12.2)$ & 0.58 \\
\hline $8-12$ years age group & $89.0(15.9)$ & $90.1(15.5)$ & 0.76 \\
\hline \multicolumn{4}{|l|}{ PedsQL TM psychosocial health summary } \\
\hline $2-4$ years age group & $83.0(16.4)$ & $91.6(10.9)$ & 0.01 \\
\hline 5-7 years age group & $81.2(12.3)$ & $89.2(10.5)$ & 0.01 \\
\hline 8-12 years age group & $84.0(14.8)$ & $89.7(13.4)$ & 0.08 \\
\hline
\end{tabular}

${ }^{a}$ Mean(standard deviation)

bStudent's t test 
Correlation of asthma severity parameters and quality of life scores in siblings

Among the siblings in the 2-4 years old age group, neither the physical $(r=0.03 p=0.86)$, emotional $(r=-0.13 p=0.44)$, social $(r=0.18$ $\mathrm{p}=0.30)$, school $(\mathrm{r}=0.36 \mathrm{p}=0.42)$ domain scores nor the total QoL score $(r=-0.004$ $\mathrm{p}=0.98)$ was correlated with age at asthma diagnosis. Similarly, there was no correlation of any of the QoL scores with the number of emergency visits or asthma exacerbations $(r<0.26$ and $\mathrm{p}>0.05$ for all $)$.

Among the siblings in the 5-7 years old age group, total QoL score was not correlated with age at asthma diagnosis, number of emergency visits and number of asthma exacerbations
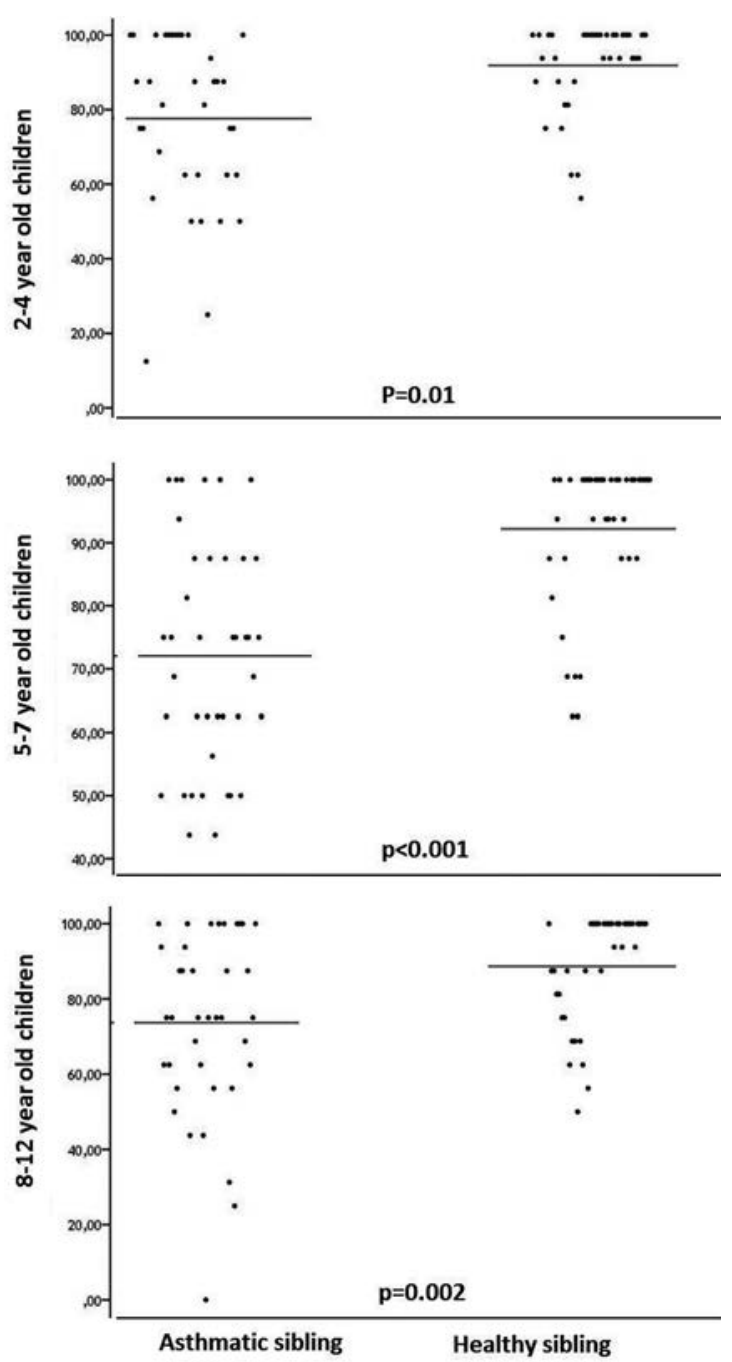

Fig. 1. Comparison of emotional subscore of PedsqL $\mathrm{L}^{\mathrm{TM}}$ in children with an asthmatic and healthy sibling. $(\mathrm{r}=0.08 \mathrm{p}=0.67, \mathrm{r}=0.05 \mathrm{p}=0.76, \mathrm{r}=0.05$ $\mathrm{p}=0.76$ respectively). Moreover, none of the QoL domain scores in these siblings were correlated with asthma severity parameters listed.

Similar results were obtained for the siblings in the 8-12 years old group and total QoL score was not correlated with age at asthma diagnosis, number of emergency visits and number of asthma exacerbations $(\mathrm{r}=0.31 \mathrm{p}=0.06, \mathrm{r}=0.06$ $\mathrm{p}=0.74, \mathrm{r}=0.04 \mathrm{p}=0.82$ respectively).

\section{Discussion}

The results of our study suggested that emotional domain of quality of life is lower in siblings of asthmatic children compared to children with healthy siblings. On the other hand, physical, social or school domains of QoL are not different from those in the siblings of healthy children. Moreover, none of the QoL scores in the siblings were correlated with asthma control parameters.

Chronic diseases in children impact not only the patients themselves but also their families including parents and siblings ${ }^{4-6,8,16-19}$. Despite the fact that both chronic disease in the child and impaired QoL and psychosocial status of parent influences QoL in the sibling negatively, this area is not studied as extensively in asthma. However, it is reported that siblings of children with chronic diseases experience higher psychological especially internalizing problems as well as impaired cognitive development 18. This is in accordance with our findings that showed lower emotional quality of life in siblings of children with asthma. There are many possible explanations such as feelings of neglect and less attention in the sibling due to the various medical needs of the asthmatic child ${ }^{8}$. We have not assessed behavior problems in our study however a previous study reported that in siblings of chronically ill children, emotional problems are associated with decreased psychological, family, physical and total QoL ${ }^{18}$. Moreover, the authors demonstrated that these problems decreased with family rehabilitation ${ }^{17}$. Chronic illnesses reported in this study were mostly cystic fibrosis, congenital heart disease and cancer; therefore, it may be an important future research area for siblings of children with asthma. 
In a study that assessed quality of life in siblings of children with cancer demonstrated that, motor and cognitive skills as well as negative and positive emotions domains of QoL were impaired partially showing concordance with our results ${ }^{16}$. The difference between the physical QoL results may be attributed to the use of different QoL scales since they used TNO-AZL children's QoL questionnaire and also to the difference in nature of cancer and asthma. However, despite these differences emotional QoL seems to be impaired in both studies.

Previous research that assessed psychosocial outcome in family members of children with sickle cell disease is strongly associated with emergency visits ${ }^{19}$. However, we have not found a significant association between emergency visit and QoL in healthy siblings of children with asthma. This difference in results might be attributed to difference in diseases and difference in outcome parameters which was QoL in our study whereas psychological problems in the reference study ${ }^{19}$. We would have expected a significant correlation of clinical parameters and emotional QoL since that domain of QoL was significantly lower in siblings of asthmatic children. However, our results did not show such correlation. This might be attributed to the fact that children enrolled did not have severe asthma findings. Moreover, as reported by the authors, family functioning is an important mediator of psychological outcome in healthy siblings of children with sickle cell disease and we have not assessed family functioning in our population; this might have also led to differences in results.

The major limitation of our study was the parent reported nature of the PedsQL ${ }^{\mathrm{TM}}$ Short Form 15 questionnaire, because it is well known that parental report of QoL might not agree with the child's own report. Parental reports were reported to be more negative than children's reports ${ }^{8}$. This limitation existed for children in both healthy and asthmatic groups however parents of asthmatic children might have a more negative view of their situation due to the awareness of their condition. Therefore, this limitation must be considered when drawing conclusions from our results. Another limitation, this study enrolled siblings of children who presented to a tertiary care center which might have reduced the generalizability of results. Finally, asthma control of the sibling assessed by asthma control test might have added information to the disease severity level. In conclusion, emotional aspect of QoL in siblings of children with asthma is significantly reduced however physical or social aspects of QoL do not seem to be influenced much. The reduction in emotional QoL is not correlated with disease severity therefore might pose a problem even in siblings of children with controlled asthma. Therefore, vulnerability of these children needs to be considered in general pediatric practice and families need to be informed.

\section{REFERENCES}

1. Yuksel H, Sogut A, Yilmaz O, Demet M, Ergin D, Kirmaz C. Evaluation of sleep quality and anxietydepression parameters in asthmatic children and their mothers. Respir Med 2007; 101: 2550-2554.

2. Yilmaz O, Sogut A, Gulle S, Can D, Ertan P, Yuksel $\mathrm{H}$. Sleep quality and depression-anxiety in mothers of children with two chronic respiratory diseases: asthma and cystic fibrosis. J Cyst Fibros 2008; 7: 495-500.

3. Arafa MA, Zaher SR, El-Dowaty AA, Moneeb DE. Quality of life among parents of children with heart disease. Health Qual Life Outcomes 2008; 6: 91.

4. Goldbeck L. The impact of newly diagnosed chronic paediatric conditions on parental quality of life. Qual Life Res 2006; 15: 1121-1131.

5. Greenley RN, Cunningham C. Parent quality of life in the context of pediatric inflammatory bowel disease. J Pediatr Psychol 2009; 34: 129-136.

6. Hatzmann J, Heymans HS, Ferrer-i-Carbonell A, van Praag BM, Grootenhuis MA. Hidden consequences of success in pediatrics: parental health-related quality of life--results from the Care Project. Pediatrics 2008; 122: e1030-e1038.

7. Wiedebusch S, Konrad M, Foppe H, et al. Health-related quality of life, psychosocial strains, and coping in parents of children with chronic renal failure. Pediatr Nephrol 2010; 25: 1477-1485.

8. Barlow JH, Ellard DR. The psychosocial well-being of children with chronic disease, their parents and siblings: an overview of the research evidence base. Child Care Health Dev 2006; 32: 19-31.

9. Besier T, Hölling H, Schlack R, West C, Goldbeck L. Impact of a family-oriented rehabilitation programme on behavioural and emotional problems in healthy siblings of chronically ill children. Child Care Health Dev 2010; 36: 686-695.

10. Limbers CA, Skipper S. Health-related quality of life measurement in siblings of children with physical chronic illness: a systematic review. Fam Syst Health 2014; 32: 408-415. 
11. Sharpe D, Rossiter L. Siblings of children with a chronic illness: a meta-analysis. J Pediatr Psychol 2002; 27 : 699-710.

12. Robinson PD, Van Asperen P. Asthma in childhood. Ped Clin North Am 2009; 56: 191-226.

13. Papadopoulos NG, Arakawa H, Carlsen KH, et al. International consensus on (ICON) pediatric asthma. Allergy 2012; 67: 976-997.

14. Chan KS, Mangione-Smith R, Burwinkle TM, Rosen M, Varni JW. The PedsQL: reliability and validity of the short-form generic core scales and Asthma Module. Med Care 2005; 43: 256-265.

15. Yilmaz O, Turkeli A, Karaca O, Yuksel H. Evaluation of the influence of an asthmatic sibling on the quality of life in children using the Turkish version of PedsQL short form 15. Turk Arch Ped 2013; 48 (Suppl): 9.
16. Houtzager BA, Grootenhuis MA, Hoekstra-Weebers JE, Last BF. One month after diagnosis: quality of life, coping and previous functioning in siblings of children with cancer. Child Care Health Dev 2005; 31: 75-87.

17. Besier T, Hölling H, Schlack R, West C, Goldbeck L. Impact of a family-oriented rehabilitation programme on behavioural and emotional problems in healthy siblings of chronically ill children. Child Care Health Dev 2010; 36: 686-695.

18. Vermaes IP, van Susante AM, van Bakel HJ. Psychological functioning of siblings in families of children with chronic health conditions: a meta-analysis. J Pediatr Psychol 2012; 37: 166-184.

19. Gold JI, Treadwell M, Weissman L, Vichinsky E. The mediating effects of family functioning on psychosocial outcomes in healthy siblings of children with sickle cell disease. Pediatr Blood Cancer 2011; 57: 1055-1061. 